\title{
Pharmacogenomic considerations in the opioid management of pain
}

\author{
Paul J Jannetto ${ }^{1 *}$ and Nancy C Bratanow ${ }^{2}$
}

\begin{abstract}
Physicians continue to struggle with the clinical management of pain, in part because of the large interindividual variability in the efficacy, occurrence of side effects and undesired severe adverse drug reactions from the prescribed analgesics. Pharmacogenomics, the study of how an individual's genetic inheritance affects the body's response to medications, has an important role and can explain some of this interindividual variability. Genetic identification of known variant alleles that affect the pharmacokinetics or pharmacodynamics of medications used for pain management can enable physicians to select the appropriate analgesic drug and dosing regimen for an individual patient, instead of empirical selection and dosing escalation. In this article, clinically relevant pharmacogenomic targets for the management of opioid pain, including efflux transporters, proteins that metabolize drugs, enzymes that regulate the neurotransmitters that modulate pain, and opioid receptors, will be reviewed.
\end{abstract}

\section{Current management of pain}

The control of pain, a complex and subjective experience, is critical to clinical success in caring for patients. Opioids such as oxycodone, methadone and morphine are the recommended therapy by the World Health Organization and the European Association for Palliative Care for moderate to severe pain [1,2]. However, the use of opioids in pain management requires careful dose escalation and empirical adjustments based on clinical response and the presence of side effects or adverse drug reactions (ADRs). Unfortunately, successful pain management treatment - defined as adequate analgesia without

*Correspondence: jannetto@mcw.edu

'Department of Pathology, Medical College of Wisconsin, 9200 W. Wisconsin Avenue, Milwaukee, WI 53226, USA

Full list of author information is available at the end of the article excessive adverse effects [3] - can be challenging [4]. Unpleasant opioid side effects, such as nausea, vomiting, constipation and sedation, are common and can lead to absence from work, poor performance at work and the resulting risk of job loss, and a diminished quality of life. The most serious issues involve the risk of sedation, depression of respiration and unintentional death due to inability or poor ability to metabolize the medications successfully. An individual's genetic makeup may predispose the patient to these adverse effects and reduced efficacy. Pharmacogenomic approaches offer insight into the genetic variables that can affect a drug's uptake, transport, activation of its target, metabolism, interaction with other medications and excretion. The use of pharmacogenomics in patients requiring pain management can lead to more efficient opioid selection, dose optimization and minimization of ADRs to improve patient outcome.

\section{Clinically relevant candidate genes for pain management}

Cellular transporters control the uptake, distribution and elimination of drugs. P-glycoprotein is an efflux transporter also called adenosine triphosphate-binding cassette, subfamily $\mathrm{B}$, member 1 (ABCB1) or multidrug resistance 1 (MDRD1) [5]. It is expressed in hepatic, intestinal and renal epithelial cells and also on the luminal side of endothelial cells in the blood-brain barrier, and it is a major determinant of the pharmacokinetics and pharmacodynamics of several opioids (such as morphine, methadone and fentanyl) commonly used to treat pain [5]. Genetic variants (such as $3435 \mathrm{C}>\mathrm{T}$ ) in P-glycoprotein have been associated with variability of pain relief in cancer patients treated with morphine [6]. The analgesic effects of morphine are mediated by its interaction at the $\mu$-opioid receptor located in the central nervous system (CNS). P-glycoprotein can limit the concentration of pain management drugs, such as morphine, in the brain because it actively pumps drugs out of the CNS. As a result, homozygous carriers of the $3435 \mathrm{C}>\mathrm{T}$ variant (TT carriers) experience greater pain relief than heterozygous (CT) or homozygous wild-type (CC) carriers, presumably because higher concentrations 
Table 1. Clinically relevant pharmacogenomic targets for pain management

\begin{tabular}{|c|c|c|c|}
\hline Gene & Variant & Analgesics affected & Consequence of genetic variation \\
\hline$A B C B 1$ & $3435 C>T$ & Morphine & Homozygous variants cause increased efficacy \\
\hline CYP2D6 & $1846 \mathrm{G}>\mathrm{A}, 2549 \mathrm{~A}>\mathrm{del}$ & Codeine, oxycodone, tramadol & $\begin{array}{l}\text { Poor metabolizers (PM; variants) have more adverse drug reactions and less } \\
\text { efficacy }\end{array}$ \\
\hline UGT2B7 & $-840 \mathrm{G}>\mathrm{A}, 802 \mathrm{C}>\mathrm{T} ;{ }^{*} 2$ & Morphine & $\begin{array}{l}\text { Homozygous variants require lower doses of morphine for efficacy; } \\
\text { UGT2B7*2 variants have less side effects (nausea) with morphine }\end{array}$ \\
\hline COMT & 1947G>A, (Rs4680) & Morphine & $\begin{array}{l}\text { Homozygous variants have a three- to fourfold decrease in COMT activity; } \\
\text { wild-type patients require higher doses of morphine for efficacy than variant } \\
\text { patients }\end{array}$ \\
\hline OPRM1 & $118 A>G$ & Morphine, M6G & $\begin{array}{l}\text { Homozygous variants cause decreased effectiveness and increased dose } \\
\text { requirements }\end{array}$ \\
\hline
\end{tabular}

of morphine can be achieved in the CNS [6]. Table 1 lists the clinically relevant pharmacogenomic targets for pain management.

The cytochrome P450 (CYP) system is responsible for metabolizing a wide range of therapeutic agents used for pain relief. CYP2D6 is especially important for the activation or inactivation of several opioids used to treat pain, including codeine, oxycodone and tramadol [7]. Typically, the genetic variability of CYP can be grouped into four phenotypes: ultrarapid metabolizers (UM), extensive metabolizers (EM), intermediate metabolizers (IM) and poor metabolizers (PM). UM-classified patients typically contain multiple copies of a gene, which results in an increase in drug metabolism [8]. EM-classified patients are characteristic of the normal population and have a single wild-type copy of the gene, whereas IMclassified patients show decreased enzymatic activity and PM-classified patients have no detectable enzymatic activity [8]. Codeine is a prodrug that requires demethylation to its active metabolite morphine by CYP2D6 before it can exert an analgesic effect. As a result, CYP2D6 PM-classified patients experience ineffective analgesia and increased side effects from the parent drug (codeine) [7]. On the other hand, CYP2D6 UM-classified patients prescribed codeine for pain management generate extensive concentrations of morphine, which can lead to ADRs [9].

Tramadol, another opioid commonly used for pain management, produces analgesia by the synergistic action of its two enantiomers and their metabolites [7]. Tramadol undergoes metabolism by $C Y P 2 D 6$ to an active metabolite (O-desmethyl tramadol), which has greater affinity for the $\mu$-opioid receptor than does the parent compound [7]. Genetic variations in CYP2D6 have been shown to account for some of the variable pain response in the post-operative period because the CYP2D6 activity has a clinically relevant impact on the level of analgesia mediated by the $\mu$-opioid receptor [10].

Another important genetic target is uridine diphosphate-glucuronosyltransferase 2B7 (UGT2B7), which metabolizes morphine to morphine 3-glucuronide
(M3G) and morphine 6-glucuronide (M6G). The latter has a higher analgesic potency than the parent compound [11]. Morphine is commonly used to control moderate and severe pain associated with sickle cell disease. Darbari et al. [12] showed that the presence of the UGT2B7 -840G>A genotypes (GG and GA) were associated with lower M3G:morphine and M6G:morphine ratios than AA genotypes. As a result, genetic polymorphisms in UGT2B7 have been shown to decrease the hepatic clearance of morphine, which translates into lower dosage requirements of morphine [12]. In another study [13], the $U G T 2 B 7 * 2$ polymorphism $(802 \mathrm{C}>\mathrm{T})$ was also shown to be associated with the frequency of morphine-induced ADRs (nausea) in cancer patients. The authors showed that the frequency of nausea was higher in patients without the UGT2B7*2 allele [13].

Furthermore, the efficacy of opioid analgesia can be enhanced by the co-administration of catecholamines, which are involved in the modulation of pain [14]. Catechol-O-methyltransferase (COMT) is responsible for the inactivation of catecholamines (dopamine, adrenaline and norepinephrine). As a result, genetic variability in the COMT gene can contribute to differences in pain sensitivity and response to analgesics. It has been shown that a common variant allele (1947G>A; Rs4680) results in a three- to fourfold reduction in COMT enzyme activity [15]. Homozygous wild-type (GG) cancer patients required higher doses of morphine to control pain than heterozygous or homozygous variant (AA) alleles [16,17].

Finally, the $\mu$-opioid receptor encoded by the opioidreceptor-like 1 (OPRM1) gene is the primary site of action for most of the commonly used opioids. The $118 \mathrm{~A}>\mathrm{G}$ polymorphism in this gene results in less effective opioid analgesia, as reported with cancer patients with homozygous variant alleles (GG) who required higher morphine doses for pain relief than homozygous wild-type (AA) participants [18]. In another study [19], Chou et al. investigated the correlation between the $118 \mathrm{~A}>\mathrm{G}$ polymorphism and patientcontrolled morphine consumption in patients undergoing 
total knee arthroplasty. Patients who were homozygous variants (GG) consumed approximately 60\% more morphine than patients who were heterozygous or homozygous wild-type (AA) during the first 48-hour post-operative period. Patient demographics, reported pain and other factors did not differ between the genotype groups. In a similar study [20], women who had homozygous variants for the $118 \mathrm{~A}>\mathrm{G}$ polymorphism required $30 \%$ more morphine to achieve adequate pain control than those who were wild type (AA) during the first 24 hours after a total abdominal hysterectomy. Finally, a significant relationship between the degree of pain relief and the $118 \mathrm{~A}>\mathrm{G}$ genotypes was shown in cancer patients being treated with morphine over the first 2 months of therapy [6]. In the first 7 days of morphine treatment, patients homozygous for the wildtype allele (AA) had more pronounced decrease in pain from baseline than those who were homozygous variants (GG), whose response was almost undetectable [6].

\section{Limitations and future directions of pharmacogenomics for pain management}

Genomic variations clearly influence pain sensitivity, the likelihood of developing chronic pain and the response to pharmacotherapy for the management of pain [21,22]. Pharmacogenomic polymorphisms are definitely important in the interindividual variability in the analgesic effects and occurrence of ADRs of commonly used medications prescribed for pain management, but genetic factors will provide only a partial answer to the interindividual variability observed. Other factors, including biological variations (ethnicity, age and gender), environmental factors (smoking status), comorbidity and co-medications (potential for drug-drug interactions) must be considered along with the genetic variations because together they all affect the pharmacokinetics and pharmacodynamics of medications used for pain management. Additional studies are also needed to characterize the combined effects of multiple genes along with demographic and clinical variables in selecting the appropriate opioid and predicting the appropriate opioid dose in patients with pain. Large, randomized prospective studies are needed to develop appropriate dosing or treatment algorithms to facilitate the use of genotyping information appropriately by physicians. Furthermore, the continued development of regulator-approved genotyping assays to identify these variant alleles will allow greater access to this information to aid in day-to-day clinical decisions for acute and chronic pain management. The benefits of patient care and safety will result in the incorporation of this knowledge into the standard of care for anesthesiologists and pain management physicians. In the near future, pharmacogenomic approaches in pain management could lead to individualized therapy to best select the appropriate analgesic from the onset to provide sustained efficacy with the lowest side effect profile.

\section{Abbreviations}

ADR, adverse drug reaction; CNS, central nervous system; COMT, catechol-Omethyltransferase; EM, extensive metabolizer; IM, intermediate metabolizer; M3G, morphine 3-glucuronide; M6G, morphine 6-glucuronide; PM, poor metabolizer; UGT2B7, uridine diphosphate-glucuronosyltransferase 2B7; UM, ultra-rapid metabolizer.

\section{Competing interests}

PJJ has no competing interests to declare. NCB serves on the Speakers Bureau and Advisory Board of King Pharmaceuticals, Pfizer Inc. and Forest Pharmaceuticals.

\section{Authors' contributions}

PJJ and NCB drafted, read and approved the final manuscript.

\section{Authors' information}

PJJ is an Associate Professor in the Pathology Department at the Medical College of Wisconsin. He is the Director of Clinical Chemistry/Toxicology for Froedtert Hospital/Dynacare Laboratories. NCB is the Director of Midwest Comprehensive Pain Care. She is active in pain medicine and teaches on the subject.

\section{Acknowledgements}

PJJ's pharmacogenomic research interests are funded by the Pathology Department at the Medical College of Wisconsin.

\section{Author details}

'Department of Pathology, Medical College of Wisconsin, 9200 W. Wisconsin Avenue, Milwaukee, WI 53226, USA. ${ }^{2}$ Midwest Comprehensive Pain Care, 2500 N. Mayfair Rd, Suite 300, Milwaukee, WI 53226, USA.

Published: 15 September 2010

\section{References}

1. World Health Organization: Cancer Pain Relief and Palliative Care. Technical Report Series No 804. Geneva: WHO; 1990.

2. Hanks GW, Conno F, Cherny N, Hanna M, Kalso E, McQuay HJ, Mercadante S, Meynadier J, Poulain P, Ripamonti C, Radbruch L, Casas JR, Sawe J, Twycross $R G$, Ventafridda V: Morphine and alternative opioids in cancer pain: the EAPC recommendations. Br J Cancer 2001, 84:587-593.

3. Cherny N, Ripamonti C, Pereira J, Davis C, Fallon M, McQuay H, Mercadante S, Pasternak G, Ventafridda V: Strategies to manage the adverse effects of oral morphine: an evidence-based report. J Clin Oncol 2001, 19:2542-2554.

4. Chronic Pain in America: Roadblocks to Relief [http://www.ampainsoc.org/ links/roadblocks/]

5. Skorpen F, Laugsand EA, Klepstad P, Kaasa S: Variable response to opioid treatment: any genetic predictors within sight? Palliat Med 2008, 22:310-327.

6. Campa D, Gioia A, Tomei A, Poli P, Barale R: Association of ABCB1/MDR1 and OPRM1 gene polymorphisms with morphine pain relief. Clin Pharmacol Ther 2008, 83:559-566.

7. Galley HF, Mahdy A, Lowes DA: Pharmacogenetics and anesthesiologists. Pharmacogenomics 2005, 6:849-856.

8. Ingelman-Sunberg M: Pharmacogenetics of cytochrome P450 and its applications in drug therapy: the past, present and future. Trends Pharmacol Sci 2004, 25:193-200.

9. Fagerlund $\mathrm{TH}$, Braaten $\mathrm{O}$ : No pain relief from codeine? An introduction to pharmacogenetics. Acta Anaesthesiol Scand 2001, 45:140-149.

10. Stamer UM, Kehnen K, Hothker F, Wolf S, Hoeft A: Impact of CYP2D6 on postoperative tramadol analgesia. Pain 2003, 105:231-238.

11. Kilpatrick GJ, Smith TW: Morphine-6-glucuronide: actions and mechanisms. Med Res Rev 2005, 25:521-544.

12. Darbari DS, VanSchaik RHN, Capparelli EV, Rana S, McCarter R, VandenAnker J: UGT2B7 promoter variant $-840 \mathrm{G}>\mathrm{A}$ contributes to the variability in hepatic clearance of morphine in patients with sickle cell disease. Am J Hematol 2008, 83:200-202. 
13. Fujita K, Ando Y, Yamamoto W, Miya T, Endo H, Sunakawa Y, Araki K, Kodama K, Nagashima F, Ichikawa W, Narabayashi M, Akiyama Y, Kawara K, Shiomi M, Ogata H, Iwasa H, Okazaki Y, Hirose T, Sasaki Y: Association of UGT2B7 and $A B C B 1$ genotypes with morphine-induced adverse drug reactions in Japanese patients with cancer. Cancer Chemother Pharmacol 2009 [Epub ahead of print]

14. Niemi G, Greivik H: The minimally effective concentration of adrenaline in a low-concentration thoracic epidural analgesic infusion of bupivacaine, fentanyl, and adrenaline after surgery-a randomized, double-blind, dosefinding study. Acta Anaesthesio/ Scand 2003, 47:439-450.

15. Lotta T, Vidgren J, Tilgmann C, Ulmanen I, Melen K, Julkunen I, Taskinen J: Kinetics of human soluble and membrane bound catechol $\mathrm{O}$ demethyltransferase: a revised mechanism and description of the thermoliable variant of the enzyme. Biochemistry 1995, 34:4202-4210.

16. Rakvag TT, Klepstad P, Baar C, Kvam TM, Dale O, Kaasa S, Krokan HE, Skorpen F: The Val58Met polymorphism of the human catechol Odemethyltransferase (COMT) gene may influence morphine requirements in cancer pain patients. Pain 2005, 116:73-78.

17. Rakvåg TT, Ross JR, Sato H, Skorpen F, Kaasa S, Klepstad P: Genetic variation in the catechol-O-Methyltransferase (COMT) gene and morphine requirements in cancer patients with pain. Mol Pain 2008, 4:64-76.

18. Klepstad P, Rakvag T, Kaasa S, Holthe M, Dale O, Borchgrevink PC, Baar C, Vikan T, Krokan HE, Skorpen F: The 118A>G polymorphism $\mathrm{n}$ the human micro-opioid receptor gene may increase morphine requirements in patients with pain caused by malignant disease. Acta Anaesthesio/ Scand 2004, 48:1232-1239.

19. Chou WY, Yang LC, Lu HF, Ko JY, Wang CH, Lin SH, Lee TH, Concejero A, Hsu CJ: Association of mu-opioid receptor gene polymorphism (A118G) with variations in morphine consumption for analgesia after total knee arthroplasty. Acta Anaesthesio/ Scand 2006, 50:787-792.

20. Chou WY, Wang CH, Liu PH, Liu CC, Tseng CC, Jawan B: Human opioid receptor $\mathrm{A} 118 \mathrm{G}$ polymorphism affects intravenous patient-controlled analgesia morphine consumption after total abdominal hysterectomy. Anesthesiology 2006, 105:334-337.

21. Kadiev E, Patel V, Rad P, Thankachan L, Tram A, Weinlein M, Woodfin K, Raffa $\mathrm{RB}$, Nagar S: Role of pharmacogenetics in variable response to drugs: focus on opioids. Expert Opin Drug Metab Toxico/ 2008, 4:77-91.

22. Argoff CE: Clinical implications of opioid pharmacogenetics. Clin J Pain 2010, 26 Suppl 10:S16-S20.

doi:10.1186/gm187

Cite this article as: Jannetto PJ, Bratanow NC: Pharmacogenomic considerations in the opioid management of pain. Genome Medicine 2010, $2: 66$ 